\title{
Aspects of vincristine-induced neuropathy in hematologic malignancies: a systematic review
}

\author{
Marie Lindhard Madsen ${ }^{1} \cdot$ Hanne Due ${ }^{1,2} \cdot$ Niels Ejskjær ${ }^{2,3} \cdot$ Paw Jensen $^{1,4} \cdot$ Jakob Madsen $^{1} \cdot$ Karen Dybkær $^{1,2,4}$
}

Received: 29 January 2019 / Accepted: 4 June 2019 / Published online: 18 June 2019

(C) The Author(s) 2019

\begin{abstract}
Purpose Vincristine is widely used as anticancer therapy for a variety of hematological malignancies. The treatment is limited by progressive vincristine-induced neuropathy, possibly including both peripheral sensory and motor nerves, autonomic nervous functions, and the central nervous system. This dose-limiting side-effect can diminish quality of life and, furthermore, cause discontinuation of vincristine treatment. The present review elucidates the current knowledge regarding vincristine-induced neuropathy in hematologic malignancies, focusing on neuropathy assessment, clinical and molecular predictive markers, drug-drug interference, prevention, and treatment.

Methods This review is conducted by a systematic search strategy for the identification of relevant literature in the PubMed and Embase databases.

Results No clinical parameters displayed convincing potential as predictors of vincristine-induced neuropathy; however, preexisting neuropathy was consistently reported to be associated with an increased risk of neurotoxicity. In contrast, molecular markers, including polymorphisms in genes involved in the pharmacodynamics and pharmacokinetics of vincristine, displayed great potential as predictive markers of neuropathy incidence and severity. Furthermore, antifungal drugs, such as itraconazole and voriconazole, decrease the metabolism of vincristine and consequently lead to severe neuropathy when co-administered with vincristine, underscoring why fluconazole should be the antifungal drug of choice.

Conclusion Reports from the 71 included studies clearly emphasize the lack of consistency in neuropathy assessment, grading systems, and reporting, making it difficult to interpret results between studies. Thus, truer clinical and molecular markers could emerge if the consistency of neuropathy detection and reporting increases by the use of conventional standardized neuropathy assessment tools and grading scales.
\end{abstract}

Keywords Vincristine $\cdot$ Vincristine-induced neuropathy $\cdot$ Neurotoxicity $\cdot$ Hematologic malignancies $\cdot$ Biomarkers

Marie Lindhard Madsen and Hanne Due Shared first authorship.

Electronic supplementary material The online version of this article (https://doi.org/10.1007/s00280-019-03884-5) contains supplementary material, which is available to authorized users.

Karen Dybkær

k.dybkaer@rn.dk

1 Department of Hematology, Aalborg University Hospital, Sdr. Skovvej 15, 9000 Aalborg, Denmark

2 Department of Clinical Medicine, Aalborg University, Sdr. Skovvej 15, 9000 Aalborg, Denmark

3 Steno Diabetes Center North Denmark, Aalborg University Hospital, 9000 Aalborg, Denmark

4 Clinical Cancer Research Center, Aalborg University Hospital, Sdr. Skovvej 15, 9000 Aalborg, Denmark

\section{Introduction}

Vincristine is a chemotherapy drug belonging to the group of vinka alkaloids, which also includes vinblastine and vindesine, which has been widely used since its approval in 1963 [1]. The antimitotic drug is used in the treatment of several solid tumors and hematologic malignancies, including breast cancer, non-Hodgkin's lymphomas (NHL), and leukemia [2]. Vincristine exerts its anti-neoplastic effect by inhibiting polymerization of tubulin and incorporation into microtubules, which prevents mitotic spindle assembly, leading to extension of mitosis and thereby apoptosis [3, 4].

The dose-limiting side effect of vincristine is neurotoxicity, which may lead to severe peripheral sensory and motor neuropathies affecting quality of life (QOL), treatment delay, and vincristine substitution or discontinuation. The impact 
of adapted use of vincristine on outcome is debatable [5-7]. Vincristine interferes with microtubules, which are critical components of nerve axons functioning as tracks for vesiclemediated transport, and leads to axonopathy that manifests slowly and progressively [8]. Vincristine-induced neuropathy (VIN) spans a broad spectrum of dysfunctions that fall into three categories: sensory, motor, and autonomic neuropathy (Table 1). The most common is peripheral sensory and motor nerve neuropathy characterized by numbness, paresthesia, impaired balance, weakened tendon reflexes, and altered gait [9]. Autonomic dysfunctions includes constipation, paralytic ileus, urinary retention and orthostatic hypotension [10, 11]. Furthermore, several cranial nerve palsies and some central nerve system (CNS) toxicities have been reported (Table 1) [12-27], even though vincristine poorly penetrates the blood-brain barrier [28]. Although neurotoxicity is widely recognized as a common side-effect of vincristine treatment in hematologic neoplasms, little is known about the true incidence, short- and long-term manifestations and severity due to lack of consistency in detection, definition, and reporting.

Overall survival for adult hematologic cancer patients has improved during the past decades due to new treatment options, and more than $80 \%$ of children with acute lymphoblastic leukemia (ALL) are now long-term survivors [29]. This therapeutic success, however, comes with the cost of more people experiencing early- and late-onset adverse effects, consequently affecting the recovering patient's QOL, which is especially important in children with a long expected lifespan after treatment. Although the intensity of the symptoms may not be extensive, the inconvenience is not correlated, and QOL can be greatly impaired [30]. Given the increasing numbers of cancer survivors, the clinical significance of chemotherapy-induced neuropathy is increasing; consequently, clinical and molecular risk predictors, prevention and treatment options, and measuring methods are urgently warranted. In this paper, we systematically review parameters related to vincristine-induced neurotoxicity in hematologic patients, and we discuss their importance.

\section{Methods}

This review was completed according to the Preferred Reporting for Systematic Reviews and Meta-analyses (PRISMA) Guidelines [31].

\section{Search strategy and study selection}

PubMed and Embase databases were systematically searched for current literature on VIN in patients with hematologic malignancies. Supplementary Table 1 outlines the search strategy. The search was performed on 16 July 2018 and identified 1949 articles after removal of duplicates, which subsequently were manually screened based on title and abstract by two independent individuals. Articles not focusing on hematologic malignancies or vincristine-induced neuropathy were excluded as were reviews, conference abstracts, nonhuman studies, and data not published in English. The remaining articles were assessed for eligibility by full-text screening, and 71 articles were included in this systematic review after applying the same exclusion parameters (Supplementary Fig. 1).

Table 1 Types of vincristine-induced neuropathy

\begin{tabular}{|c|c|c|c|}
\hline Type & Definition & Symptoms & References \\
\hline Sensory neuropathy & Sensory nerve damage & $\begin{array}{l}\text { Paresthesia in form of numbness, tingling and pricking. Pain, impaired } \\
\text { vibration/touch sensitivity/temperature recognition }\end{array}$ & {$[9,92]$} \\
\hline Motor neuropathy & Motor nerve damage & $\begin{array}{l}\text { Motor weakness, walking difficulties, muscle cramps, weakened tendon } \\
\text { reflexes and fine motor skills }\end{array}$ & [92] \\
\hline Autonomic neuropathy & Autonomic nerve damage & Constipation, ileus, urinary retention, incontinence, hypotension & {$[11,92]$} \\
\hline Optic neuropathy & Cranial nerve II damage & Blurred vision, color vision deficiency, transient/permanent blindness & {$[12,13]$} \\
\hline Oculomotor nerve palsy & Cranial nerve III damage & Ptosis, ophthalmoplegia & {$[14-16]$} \\
\hline Abducens nerve palsy & Cranial nerve VI damage & Ptosis, strabismus, ocular muscle paresis, diplopia & {$[17,18]$} \\
\hline Facial nerve palsy & Cranial nerve VII damage & Limited movement of facial muscles and jaw & [19] \\
\hline Acoustic nerve palsy & Cranial nerve VIII damage & Hearing loss & {$[20]$} \\
\hline Ototoxicity & Cochlear damage & Decrease in frequencies, decrease of contralateral suppression amplitudes & {$[21]$} \\
\hline Hypoglossal nerve palsy & Cranial nerve XII damage & Loss of tongue movement & [19] \\
\hline Vocal cord palsy & Laryngeal nerve damage & Stridor, respiratory distress, persistent cough & {$[22,23]$} \\
\hline Encephalopathy/PRES & Cerebral dysfunction & Disorientation, hemiplegia, global aphasia, seizures & {$[24,25]$} \\
\hline SIADH & Cerebral axonal swelling & Hyponatremia, seizures, mental changes & {$[26,27]$} \\
\hline
\end{tabular}

PRES posterior reversible encephalopathy syndrome, SIADH syndrome of inappropriate antidiuretic hormone secretion 


\section{Results}

A total of 71 articles were included in this systematic review (Supplementary Fig. 1). Of these articles, 13 investigated VIN measuring methods [9, 32-43], while 11 records investigated clinical risk predictors for VIN development [44-54]. Fifteen records studied molecular risk parameters [5, 55-68]. In addition 12 records described interactions between vincristine and other drugs, mainly antifungal triazoles [1, 69-79], while 8 records addressed prevention and treatment options [10, $19,80-85]$. The remaining 12 records were of mixed character and included long-term effects, assessment of QOL, and dose-dependent VIN studies [30, 86-96].

The 71 articles include studies of VIN in both pediatric and adult hematologic malignancies, including ALL, diffuse large B cell lymphoma, follicular lymphoma, multiple myeloma, Burkitt lymphoma, anaplastic large-cell lymphoma, and Hodgkin's lymphoma. The reported frequency of vincristine-induced neurotoxicity in these studies varies tremendously from approximately $100 \%$ [34] to $10 \%$ [48] depending on patient exclusion criteria, vincristine doses and number of treatment cycles, and the methods of obtaining neuropathy information.

\section{Methods for VIN measuring}

Numerous methods for assessment of neuropathy are used in different studies. There is no gold standard, making it difficult to compare studies. This lack of a standard is most likely the reason why the reported incidence of neuropathy in patients treated with vincristine varies so significantly. In 1981, the World Health Organization (WHO) initiated a set of recommendations on standardized approaches to recording baseline data, reporting of treatment, reporting of response, and grading of acute and subacute toxicity to assess the problem that it is difficult for investigators to compare their results with those of others [97]. WHO's peripheral neuropathy score comprises 5 grades $(0-4)$; noteworthy, only two of the included studies applied WHO's neurotoxicity score [5, 65].

In 2003, the National Cancer Institute of the National Institutes of Health released the Common Terminology Criteria for Adverse Events (CTCAE), which was revised from a widely used neuropathy grading scale, named the Common Toxicity Criteria, that was developed in 1984 [98]. CTCAE is still occasionally used today [67]. However, as it was shown to underestimate both incidence and severity of neuropathy, several scores have been made to overcome this problem, including the Total Neuropathy Score (TNS) $[34,99]$. TNS consists of ten items that are both subjective and objective; however, the TNS was found to be too burdensome and time-consuming for application in everyday clinical practice and consequently reduced into a clinical version (TNSc), a reduced version (TNSr), and a neuropathy score that quite often used in pediatric patients, called the Pediatric modified Total Neuropathy Score (Ped-mTNS) [32]. The Ped-mTNS consists of the first seven items of TNS and was shown to be a reliable and valid measure of VIN in school-aged children [33]. Compared with Ped-mTNS, CTCAE version 3.0 failed to identify sensory neuropathy in $40 \%$ of subjects and significant motor neuropathy in $15 \%$ when applied on children treated for ALL, lymphoma or non-CNS solid tumors [34]. Thus, the detection method itself greatly influences the result, illustrating the need to introduce and unify detection and quantification of VIN.

A study examined the validity, reliability and clinical feasibility of several VIN measures in ALL children [35]. The study mostly concentrated on a variation of TNS, referred to as Total Neuropathy Score-Pediatric Vincristine (TNS$\mathrm{PV}$ ), which was found useful for measuring VIN in children over the age of 5 years; additionally, some of the items were responsive to change over time. Furthermore, they tested CTCAE version 4.0 and the Balis grading scale, which both presented a risk of underestimating VIN. The FACES pain scale was feasible for pain severity quantification in children of all ages. In addition to the previously established measurements, they developed a simple test V-Rex consisting of the two most responsive items, vibration and reflex, which is better than standard grading scale methods according the study [35].

Symptoms of VIN are mostly subjective; thus, selfreported data could be preferable in VIN assessment. The European Organization for Research and Treatment of Cancer (EORTC) developed a questionnaire intended to supplement the core quality of life questionnaire to assess chemotherapy-induced neuropathy (QLQ-CIPN20) [42]. The 20-item questionnaire includes information on symptoms and functional limitations, and comparison to CTCAE in two large datasets revealed a strong correlation between patients with high CTCAE grade and QLQ-CIPN20 score, documenting the validity of self-reported data in terms of chemotherapy-induced neuropathy [43].

Interestingly, studies have shown a difference between children and adults in the type of nerves that are the most affected with a predominance of sensory neuropathy in adults [90, 100, 101]. Electrodiagnostic examinations, including nerve conduction of different nerves, T-reflex measurement and needle electromyography, showed a electrophysiological and clinical motor predominance in children aged 1-17 years [39], which is consistent with other studies using nerve conduction and somatosensory evoked potentials $[9,38,41,86]$. Furthermore, a study demonstrated 
that measurements of compound muscle action potential amplitude on the median and/or peroneal nerve could objectively grade VIN in children [9]. In addition to sensory and motor, the third neuropathy modality is autonomic. Heart rate variability, reflecting a vagal nerve lesion, is useful to detect and quantify autonomic cardioneuropathy in children diagnosed with ALL [36]. Furthermore, a study used The Michigan Autonomic Symptoms Survey, but interestingly no abnormalities in autonomic functions were found [40].

Many new neurotoxicity scores have continuously been developed. Of these scores, some focus on objective findings, while others are of more subjective character. Although CTCAE still develops new versions, it seems to have been outdated by newer approaches. Despite findings suggesting motor predominance in children and sensory predominance in adults, no consensus exists on the best methods of obtaining VIN information in hematological patients of different age.

\section{Clinical predictors}

Although occurrence of neurotoxicity is high, little is known about risk factors for developing neuropathy during vincristine treatment. A consensus about possible risk factors is lacking, and numerous parameters are only studied and reported in a limited number of studies with relatively small study populations. The dose-limitation of vincristine is $1.4 \mathrm{mg} / \mathrm{m}^{2}$ in each cycle with a maximum of $2 \mathrm{mg}$ per cycle, and higher doses exert greater toxicity and questionably result in better treatment outcome [91, 92, 102]. The most consistent observation is that the severity of neuropathy increases with accumulated vincristine dose [49, 92, 103]. Furthermore, several studies report advanced age in pediatric patients as a clinical risk factor $[61,69,73]$. However, some studies do not find this correlation in pediatric or adult patients $[44,49]$ and others even suggest the opposite for both groups [54, 88, 95].

It has been suggested that neuropathy incidence could be disease dependent given that a significantly higher incidence in patients suffering from lymphoma is observed compared with nonlymphoid cancer patients (e.g., leukemia, breast cancer, malignant melanoma) [88]. Fourteen out of 23 patients with lymphoma and 5/37 patients without lymphoma developed neuropathy despite comparable dosage [88], and concordant observations were made by others [46]. A higher percentage of lymphoma patients have elevated levels of serum alkaline phosphatase, which significantly prolongs elimination of vincristine and results in longer vincristine exposure and associated toxicities [46]. Furthermore, the results from this study indicate that area under the vincristine plasma concentration time curve and elevated serum alkaline phosphatase are predictors of VIN [46]; however, the latter observation is contradicted in a study of
26 patients reporting that serum alkaline phosphatase is not important [92].

Several factors have been suggested as possible predictors for VIN. A study from 2010 aimed to identify predictors for chemotherapy-induced peripheral neuropathy, including vincristine, in 52 patients [49]. It was discovered that the number of chemotherapy cycles was a predictor of VIN, whereas age and coadministration with nonsteroidal antiinflammatory drugs did not correlate with neuropathy incidence and severity. Consistently, Anghelescu et al. observed no difference in age between ALL patients with or without neuropathy development [44]. No differences in sex, BMI group, initial leukocyte count, ALL immunophenotype, DNA index, or different genetic translocations were noted. The only significant clinical predictive variable observed was white non-Hispanic race [44].

Another study focused on the potential effect of micronutrient deficiency on VIN by measurement of serum vitamin $\mathrm{E}$, vitamin $\mathrm{B}_{12}$ and folate together with nerve conduction studies at a mean 20 months after the last vincristine injection; however, no significant association was observed [45]. Furthermore, the impact of liver dysfunction was examined in two independent studies, where one recommended reduced vincristine dosage [46] whereas the other did not [88].

Despite the fact that some records mention diabetes mellitus as a risk factor for developing VIN [103-105], thorough studies are lacking. Patients with diabetes are at risk of diabetic neuropathy; therefore, it could be logical to assume that diabetic patients are at higher risk for VIN. Noteworthy, diabetic neuropathy is a long-term risk of diabetes; therefore, it is important to be aware of the difference between diabetes as a risk factor and diabetic neuropathy as a secondary risk factor.

Hyperglycemia is a common side-effect of corticosteroid therapy that is often noted with vincristine treatment and potentially leads to diabetes [106]. The effect of hyperglycemia was studied in 278 patients with ALL during induction chemotherapy regimens including vincristine [48]. Hyperglycemia was defined as glucose level $\geq 200 \mathrm{mg} / \mathrm{dL}$ on $\geq 2$ determinations, and the study included 20 patients $(7 \%)$ previously diagnosed with diabetes. Statistically significant differences in peripheral neuropathy were not noted between 103 patients with hyperglycemia and the 175 patients without; furthermore, a subanalysis of patients with previously diagnosed diabetes or elevated baseline blood glucose did not reveal any differences. Consistently, no difference in neuropathy incidence was found when comparing diabetic patients requiring diabetic medications with nondiabetic patients [54].

Furthermore, the consequences of hyperglycemia in elderly patients were examined and included 162 patients with NHL treated with vincristine among other 
chemotherapeutic drugs [47]. The authors found that baseline hyperglycemia, stage, creatinine clearance and hyperglycemia during chemotherapy was associated with grade 3-4 toxicity of 18 symptoms, including neuropathy, diarrhea, fatigue and pneumonia, without separate and focused analysis of the individual symptoms.

The risk of severe neurotoxicity due to other forms of pre-existing diseases than diabetes is more substantiated. Care should be taken when administrating vincristine to Charcot-Marie-Tooth disease (CMT) patients, the most common hereditary neuropathic disease. A clinical challenge is undiagnosed cases of CMT, and seeking information about family history of CMT before initiating chemotherapy with vincristine could possibly prevent patients from severe neuropathy given that pediatric ALL often is diagnosed before the age of 10 and CMT after the age of 10 [51]. Pediatric and adult cancer patients are at risk of undiagnosed CMT [50]. Even small doses of vincristine that are normally not associated with neuropathy can cause exaggerated and irreversible neuropathy in these patients [50]. Another form of neuropathy presenting clinical problems is the autoimmune Guillain-Barré syndrome (GBS). Acute onset GBS can be difficult to differentiate from VIN, and this differential diagnoses is important to have in mind as GBS can be treated with immunoglobulins. Uncertainty still remains whether GBS and VIN can exaggerate one another [52, 53].

This section clearly emphasizes the inconsistency between studies; however, clinical parameters, including white non-Hispanic race and preexisting neuropathy, such as CMT, are consistently reported in more than one study to predict increased risk of VIN. When assessing the currently available literature, preexisting diabetes does not increase the risk of VIN. Hyperglycemia presenting during induction chemotherapy or later in the course of chemotherapy also does not increase the risk of VIN.

\section{Molecular predictors}

The hepatic cytochrome P450 3A (CYP3A) enzyme subfamily is the most important system for drug metabolism. Vincristine is primarily metabolized by CYP3A4 and CYP3A5, of which the latter is considerably more effective [107]. Given that $60 \%$ of African-Americans express the CYP3A5 enzyme compare with 33\% of Caucasians [108], several studies have investigated race-specific genotypes and tested whether African-Americans metabolize vincristine more effectively, resulting in lower vincristine exposure and associated toxicities (Table 2). A retrospective study analyzed 92 Caucasian and 21 African-American pediatric ALL patients and identified VIN symptoms in 35\% of Caucasians compared with 5\% of African-Americans [57]. Additionally, Caucasians experienced more severe vincristine-associated neuropathy and had more reductions in total doses. However, it is important to highlight that race is used as a surrogate for the CYP3A5 genotype, and no genotyping was conducted.

The most common genetic germline polymorphisms are $C Y P 3 A 4 * 1 B, C Y P 3 A 5 * 3$, and $C Y P 3 A 5 * 6$, of which the latter two variants induce splice variants and protein truncation leading to substantially decreased expression of CYP3A5 in the liver [108]. Increased incidence of VIN has been observed in patients who expressed $C Y P 3 A 5 * 3$; although the percentage of African-Americans expressing $C Y P 3 A 5 * 3$ was greater than Caucasians, the difference did not reach statistical significance potentially due to the small sample size [64]. Furthermore, a higher incidence of neuropathy was detected in Caucasians (81\%) than African-Americans (77\%); however, substantially higher frequencies were noted for both ethnicities compared with the study by Renbarger et al. [57] (Table 2).

CYP3A variants were determined by others without focusing on ethnicity $[55,56,59,66,67]$ (Table 2). The CYP3A5 genotype was studied in 78 Kenyan children with different cancer diagnoses [67]. Seventy-one of the 78 subjects $(91 \%)$ were homo- or heterozygous for the CYP3A5*1 allele, which are phenotypic identical and lead to high expression of CYP3A5. Children with genotypes causing low CYP3A5 expression had significantly higher detectable vincristine levels in plasma compared with high expressers. Regardless of several neuropathy assessment tools, minimal neuropathy was detected, and no difference in neuropathy incidence or severity was observed despite differences in vincristine plasma concentrations. Noteworthy, Kenyan children experienced negligible VIN compared with US children despite receiving at least 33\% more vincristine at baseline due to protocol-specific dosing [67], indirectly supporting the observations of race and CYP3A genotype.

Genotyping of 105 Caucasian children with ALL revealed that $82 \%$ of the patient are low CYP3A5 expressers (CYP3A5*3 genotype) with a higher incidence and severity of vincristine-induced side effects and more reductions of vincristine compared with CYP3A5 expressers [59]. Thus, the $C Y P 3 A 5^{*} 3$ genotype causes increased vincristine exposure, leading to higher neuropathy incidence and severity grade; however, information on clinical impact was not reported.

Studies to date have focused on genetic variants of genes involved in the pharmacokinetics of vincristine. Other biological processes can also affect VIN; hence, polymorphisms in microRNAs regulating vincristine-related genes have been examined [5]. A mutation in the seed region of miR-3117 was detected that could affect binding to the drug transporter genes $\mathrm{ABCC} 1$ and RALB1, which are predicted to be targets of miR-3117 in at least six prediction databases and consequently affect the regulation and expression of the targets. In addition, they identified a mutation causing alteration of 


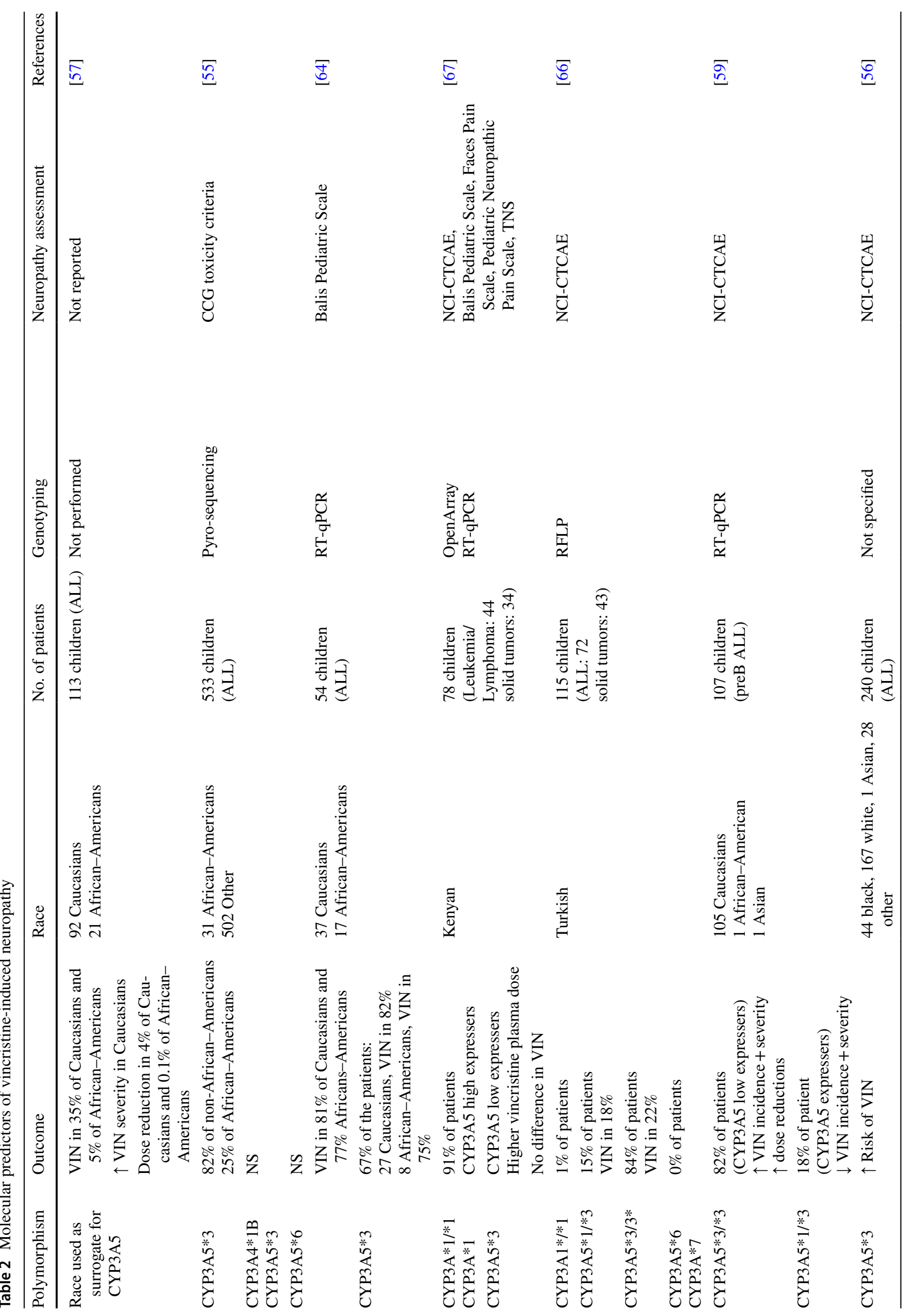




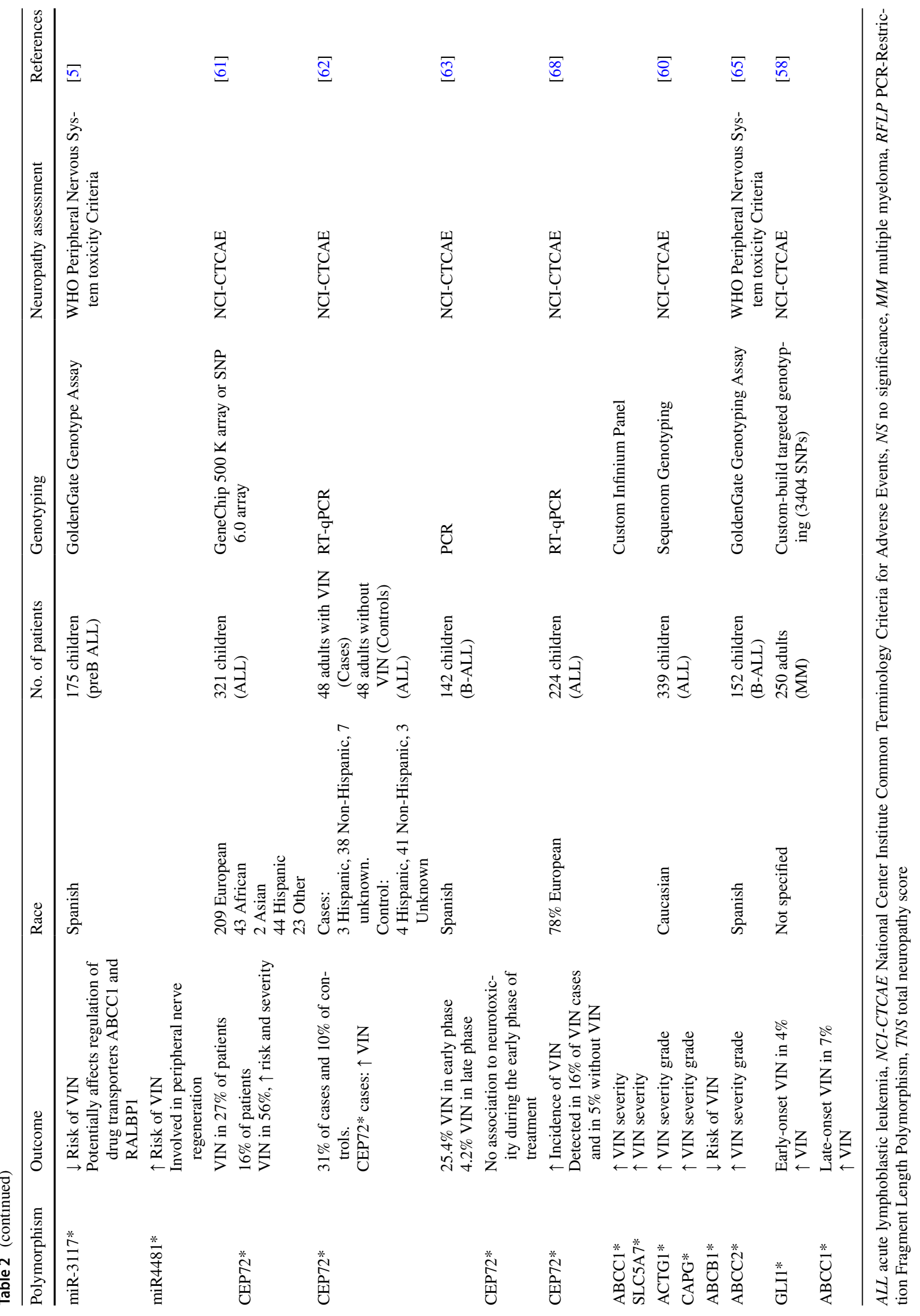


the secondary structure of miR-4481a mutation, which is potentially involved in peripheral nerve generation. Consistently, polymorphisms in $\mathrm{ABCC} 1$ and $\mathrm{ABCB} 1$ drug transporters correlate with neurotoxicity, which also applies to ACTG1 and CAPG1 polymorphisms that are targeted upon vincristine treatment $[60,68]$. By dividing VIN into earlyand late-onset, it was observed that early-onset neurotoxicity was associated with upregulation of genes and SNPs in genes involved in cell cycle and proliferation, whereas lateonset neurotoxicity was characterized by polymorphisms in genes involved in absorption, distribution, metabolism and excretion [58].

A study was conducted for the identification of genetic germline variants associated with the occurrence and severity of VIN in 321 pediatric ALL patients using Affymetrix GeneChip $500 \mathrm{~K}$ or SNP 6.0 array [61]. They identified a SNP in the promoter region of CEP72 that encodes a centrosomal protein essential for microtubule formation, which is directly involved in the mechanism of action of vincristine. This mutation introduces a binding site for transcriptional repression leading to lower expression of CEP72, which causes microtubule instability and increased vincristine sensitivity [61]. The CEP72 variant was observed in 50 of 321 pediatric ALL patients, which had a significantly higher incidence and severity grade of neurotoxicity that was consistent with findings of others [68]. Furthermore, they examined the variant in adult ALL patients using a case-control setup with 48 patients who developed VIN and 48 who did not, which confirmed the high incidence of neurotoxicity in CEP72 variant patients [62]. Consistent with these findings, the potential of the CEP72 variant as a marker of VIN was investigated in Spanish ALL-diagnosed children; however, no association was found [63]. The inconsistency between studies could be due to population differences and the fact that the studies by Diouf et al. [61] focused on neuropathy in the later phase of treatment compared with the early phase in the study by Gutierrez-Camino et al. [63]. As no association was found, they conducted another study analyzing SNPs in 8 genes and 13 miRNAs involved in vincristine pharmacokinetics, which revealed strong association between neurotoxicity and polymorphisms in ABCC2 [65].

Several genes involved in the pharmacokinetics and pharmacodynamics of vincristine display potential as predictive markers of VIN risk. Thus, genotyping can be useful to guide individualized treatment to maximize the therapeutic benefit and avoid unnecessary toxicity even if the role of race and early/late VIN remains incompletely characterized.

\section{Drug-drug interference}

Concomitant administration of drugs always carries the risk of drug-drug interaction. This effect can delay, decrease or enhance the absorption or metabolism of either drug, consequently affect the drug action and cause adverse effects. A major cause of morbidity and mortality in patients with hematological malignancies treated with immunosuppressive protocols are invasive fungal infections [70]. Antifungal triazole drugs, such as fluconazole, itraconazole and voriconazole, are the main agents for prophylaxis and treatment [1], and itraconazole is preferred given its broader spectrum of activity, especially against Aspergillus infections [75]. Unfortunately, the combination of vincristine and itraconazole has proven unfortunate (Table 3 ).

Several case reports and retrospective studies describe the outcome of VIN when antifungal triazoles are co-administered $[1,69-76]$. This interaction is mostly described in pediatric ALL patients but is also seen in adults (Table 3). Especially during chemotherapy induction, children are at increased risk of fungal infections due to neutropenia and corticosteroid administration; therefore, antifungal prophylaxis could be worth considering [69]. This interaction was first described in 1995 where 4 out of 14 adults experienced severe neurotoxicity during vincristine induction therapy and antifungal prophylaxis with itraconazole [72]. The prescribed itraconazole dose in this report was $400 \mathrm{mg} /$ day; however, the same outcome has been observed and reported in several other cases treated with lower doses (Table 3). The study compared neurotoxic complications with a previous series of 460 ALL patients treated with an identical cytostatic regimen and found that the incidence of VIN enlarged and the symptoms were more severe. This severely aggravated neurotoxicity is also described by others [70, 75]; in addition, CNS toxicity has been recorded in $30 \%$ of the patients receiving itraconazole [76].

As mentioned, vincristine is metabolized by CYP3A. Fluconazole and itraconazole inhibit the action of CYP3A, and the former is far less potent than itraconazole [109]. Furthermore, itraconazole inhibits the P-glycoprotein efflux pump, a vincristine transporter, resulting in higher intracellular vincristine concentrations [110]. Thus, coadministration of vincristine and itraconazole decreases the metabolism of vincristine to a greater extent than coadministration with fluconazole, causing notably enhanced neurotoxicity. Consistently, three studies did not observe significant differences in neuropathy upon fluconazole treatment $[69,71$, 73], whereas six independent studies report higher incidence and severe neuropathy upon itraconazole treatment $[1,70$, 72, 74-76] (Table 3).

A study by Yang et al. found that coadministration of vincristine with itraconazole or voriconazole resulted in a significantly higher incidence of vincristine-associated adverse effects than in patients treated with fluconazole and control patients only treated with vincristine [1]. Additionally, they found that the incidence of VIN was significantly higher in itraconazole-treated patients compared with patients treated with voriconazole. 
Table 3 Drug-drug interactions with antifungal drugs

\begin{tabular}{|c|c|c|c|c|c|}
\hline Drug & Dose & Diagnosis & No. of patients & Neurotoxic outcome & References \\
\hline Fluconazole & $\begin{array}{l}4 \mathrm{mg} / \mathrm{kg} / \text { day } \\
\max 200 \mathrm{mg} / \text { day } \\
5 \text { patients: } \\
300-400 \mathrm{mg} / \text { day }\end{array}$ & ALL & 197 children & NS & [69] \\
\hline Fluconazole & $4 \mathrm{mg} / \mathrm{kg} /$ day & ALL & 31 children & NS & [73] \\
\hline $\begin{array}{l}\text { Fluconazole Voriconazole } \\
\text { Fluconazole and vori- } \\
\text { conazole }\end{array}$ & Not stated & $\begin{array}{l}\operatorname{ALL}(n=114) \\
\operatorname{HL}(n=16)\end{array}$ & 130 patients $<22$ y/o & NS & [71] \\
\hline Fluconazole & $8 \mathrm{mg} / \mathrm{kg} /$ day iv $(n=42)$ & ALL & 136 cases & NS & {$[1]$} \\
\hline Itraconazole & $5 \mathrm{mg} / \mathrm{kg} /$ day os $(n=44)$ & & & VIN, CNS, autonomic & \\
\hline Voriconazole & $\begin{array}{l}8 \mathrm{mg} / \mathrm{kg} / \text { day capsules } \\
(n=6)\end{array}$ & & & $\begin{array}{l}\text { VIN severity: Itracona- } \\
\text { zole > voriconazole }\end{array}$ & \\
\hline Fluconazole & $5 \mathrm{mg} / \mathrm{kg} /$ day $(n=1)$ & ALL & 20 children & NS & [76] \\
\hline Itraconazole & $5 \mathrm{mg} / \mathrm{kg} /$ day $(n=16)$ & & & VIN, CNS, SIADH, ileus & \\
\hline Voriconazole & $14 \mathrm{mg} / \mathrm{kg} /$ day iv $(n=3)$ & & & VIN & \\
\hline Itraconazole & 400 mg/day capsules & ALL & $\begin{array}{l}14 \text { patients } \\
16-29 \mathrm{y} / \mathrm{o}\end{array}$ & Severe VIN, ileus & {$[72]$} \\
\hline Itraconazole & $5 \mathrm{mg} / \mathrm{kg} /$ day capsules & $\begin{array}{l}\operatorname{ALL}(n=7) \\
\text { B-cell NHL }(n=1) \\
\text { T cell NHL }(n=1)\end{array}$ & 9 children & $\begin{array}{l}\text { VIN, autonomic, seizures, } \\
\text { SIADH }\end{array}$ & [75] \\
\hline Itraconazole & 200 mg/day capsules & ALL & $\begin{array}{l}2 \text { patients } \\
19 \text { and } 55 \mathrm{y} / \mathrm{o}\end{array}$ & Autonomic, SIADH & {$[74]$} \\
\hline Itraconazole & $200 \mathrm{mg} /$ day os & $\begin{array}{l}\text { ALCL }(n=1) \\
\text { DLBCL }(n=3) \\
\text { FL }(n=1) \text { unspeci- } \\
\text { fied lymphoma } \\
(n=2)\end{array}$ & 7 adults & Severe VIN, ileus & {$[70]$} \\
\hline
\end{tabular}

$A L C L$ anaplastic large cell lymphoma, $A L L$ acute lymphoblastic leukemia, $D L B C L$ diffuse large B-cell lymphoma, $F L$ follicular lymphoma, $H L$ Hodgkin's lymphoma, $i v$ intravenous, $N H L$ non-Hodgkin's lymphoma, $N S$ no significance, os oral solution, SIADH syndrome of inappropriate antidiuretic hormone secretion, $y / o$ years old

Numerous drugs are capable of CYP3A inhibition/induction and consequently have the potential to interfere with vincristine. Protease inhibitor-based antiretroviral therapy, such as ritonavir, causes excessive neurotoxicity when coadministered with vinblastine, another vinka alkaloid, due to CYP3A4 inhibition [77, 78]. Furthermore, a study from a 1996 report on drug-drug interactions between colonystimulating factors and vincristine indicated that the underlying mechanisms for the observed induced neuropathy is not thoroughly studied; to our knowledge, the mechanism not been reported to date [79].

Drug interactions should always be kept in mind when administering more than one drug but especially when administering toxic drugs, such as chemotherapy. When using vincristine, which is almost completely metabolized by the liver, it is important to be aware of concomitant use of a drug that is also metabolized by CYP3A. Fluconazole should be preferred over both voriconazole and itraconazole for antifungal prophylaxis or treatment given that itraconazole especially has the potential to cause severe neurotoxicity.

\section{Prevention and treatment}

Vincristine-induced neuropathy can be momentary and reversible; however, it is occasionally irreversible [87, 89]. Regardless, neuropathy may consequently necessitate dosereduction or cessation, thus reducing the treatment efficacy and potentially shortening the overall survival time. Another perspective is that neuropathy can significantly impact the QOL [94], and neuropathy severity does not necessarily correlate with how much it affects the patient [30]. These problems can potentially be overcome by identifying substances with the ability to prevent and/or treat neuropathy.

Several agents have been suggested and tested for prevention and treatment of VIN; however, the results have not been promising. Currently, convincing evidence of useful pharmacologic interventions is lacking.

A study provides information on the beneficial effects from bracing and physical therapy to prevent fixed contractures/surgery when suffering from peroneal nerve palsy [80]. An older study from 1992 proposed Org 2766, a corticotropin (4-9) analogue, as a means to ameliorating vincristine neuropathy 
and additionally observed higher neurotoxicity in the placebo group [81]. Another study did not find Org 2766 to be neuroprotective [85].

Gabapentin has been tested both as prophylaxis and treatment in pediatric ALL; however, no conclusions could be made other than gabapentin did not prevent the recurrence of neuropathic pain [44]. Moreover, analgesic adjuvants given to reduce neuropathy symptoms did not show adequate prophylactic efficacy [49].

Pyridoxine (vitamin B6) and pyridostigmine (acetylcholinesterase inhibitor) have been used in the treatment of different types of VIN. Treatment of 4 ALL patients with pyridoxine and pyridostigmine for sensorimotor polyneuropathy resulted in full recovery 1-2 weeks after treatment initiation [82]. In agreement, a case study presented an ALL patient who on day 61 was diagnosed with bilateral cranial nerve VII and XII palsy and subsequently treated with intravenous pyridoxine, and complete recovery of symptoms was achieved after 2 weeks of treatment [19]. In both reports, uncertainty remained regarding whether pyridoxine/pyridostigmine was responsible for the resolution as it could have been a consequence of vincristine discontinuation.

To evaluate potential preventive effects of glutamic acid, a randomized study was conducted on 94 children diagnosed with hematological malignancies and 12 with Wilms tumor who received either glutamic acid ( $1.5 \mathrm{~g}$ /day divided into 3 doses) or placebo [10]. They found a statistically significant difference between the two groups when assessing paresthesia, patellar/Achilles reflexes, and frequency of constipation but not until the third and fourth visit, suggesting that glutamic acid may improve tolerance of vincristine. In contrast, a larger randomized study in which 200 children with ALL or NHL and 50 children with Wilms tumor or rhabdomyosarcoma received either preventive glutamic acid $(250 \mathrm{mg}$ capsules 3 times a day, body surface area $<1 \mathrm{~m}^{2}=1$ capsule, $>1 \mathrm{~m}^{2}=2$ capsules) or placebo did not find a statistically significant difference in any parameters [83]. Another similar amino acid, glutamine, has shown possible beneficial effects on sensory neuropathy and self-reported QOL [84]. The study included 31 children with hematological malignancies and 18 children with nonhematological malignancies, which were only analyzed as one group.

Due to the high prevalence of VIN, it would be of great significance to find possible prevention or treatment measures. Unfortunately, it has not been possible to find a substance with this property in current studies. Many of the substances are only tested a few times and in small studies, but glutamine could display potential if further studied.

\section{Discussion}

This systematic review identified a total of 71 studies addressing the circumstances concerning VIN in hematological patients. Although this subject obviously contains many aspects, almost none of the findings are clear-cut. In general, more research is needed given that VIN can necessitate treatment alterations and possibly last for a long period of time, significantly impacting QOL.

In addition to a cumulative dose, this systematic review did not find consistency for any clinical predictors potentially due to differences in cohort sizes, vincristine doses and cycles, and neuropathy assessment tools. In addition, several studies include patients with different cancer diagnoses, which potentially could introduce a bias given that vincristine interacts differently with cancers $[46,88]$. Consequently, further studies in larger settings are urgently warranted to fully elaborate the impact of these clinical parameters.

Caution is important with patients already suffering from CMT; however, the rareness and common time of diagnosis of this condition make it troublesome. A simple self-reporting checklist, which is not expensive or time-consuming for hospital staff, could be helpful to identify undiagnosed CMT patients before administrating vincristine [50].

With the greater attention towards molecular importance, the existence of molecular predictors present promise. Studies of molecular predictors differed in genotype detection technique and neuropathy detection method and grading, which complicated the general cross-comparison of the studies. Despite these differences, variants in the vincristine metabolizer CYP3A5 leading to reduced CYP3A5 expression were consistently reported as a risk factor for VIN (Table 2). Noteworthy, the frequency of CYP3A5 variants varies between ethnicities; consequently, the reported incidence of VIN is higher in Caucasians than African-Americans. Thus, ethnicity could be used as a risk factor for VIN; however, it is important to emphasize that it is only a surrogate for CYP3A5 and that individual genotype assessment is preferable. In addition to vincristine metabolizers, genetic alterations in genes involved in vincristine pharmacodynamics were associated with VIN. A SNP in CEP72 showed great promise as predictor of VIN in two independent ALL cohorts $[62,68]$ but failed stratification in a Spanish ALL cohort [63]. Molecular risk factors clearly contribute to a better understanding of vincristine neurotoxicity and are potentially useful in the identification of individuals at higher risk, which could optimize and personalize vincristine dosing, leading to maximum response while minimizing the risk of long-term neuropathy.

The results of drug-drug interference as a cause of increased risk of VIN were very consistent and 
independent of cohort size, diagnosis and methodology. Coadministration with itraconazole and to lesser extent voriconazole is an important aspect of VIN cause and worsening (Table 3). Based on the findings included in this review, fluconazole appears safer when concomitantly used with vincristine and should be preferred as antifungal prophylaxis and treatment. Given that the mechanism of this interaction involves inhibition of CYP3A in the liver, it could be advisable to be aware of other strong CYP3A inhibitors or inducers.

Unfortunately, neither substances for preventing VIN nor treatment options have been discovered to date, resulting in substitution, reduction or discontinuation as the only method of handling neurotoxicity. Glutamic acid potentially prevents or at least improves tolerance of vincristine in one study.

In general, various neuropathy detection methods and grading systems are used for all aspects of neuropathy examined in this review, making it very difficult to compare studies and interpret the results between studies. Although the WHO had great intentions to create a standardized tool of assessing information about neuropathy, it obviously did not succeed or persist as a useful rating scale since only two of the 71 included studies used this tool. Nerve conduction studies are thought to be the most accurate method of quantifying VIN but are time consuming, costly and discomforting to be a standard VIN measurement in clinical practice. In contrast, subjective measures introduce the risk of interobservational variability. With the many new neurotoxicity scores used today, it is yet again of importance to agree on but not necessarily standardize which score fits which situation best and thereby makes it possible to compare studies.

\section{Conclusion}

In conclusion, clinical parameters did not show convincing potential as predictors of VIN. In contrast, molecular markers, including polymorphisms in the hepatic vincristine metabolizer CYP3A5, displayed great promise in predicting increased incidence and severity of neuropathy; however, further studies are warranted to assess its use in treatment prediction. Consistently, antifungal drugs, such as itraconazole and voriconazole, inhibit the action of CYP3A5; consequently, coadministration of vincristine and these drugs decreases vincristine metabolism, leading to enhanced neuropathy side effects. More true markers of both clinical and molecular origin may emerge if consistency in VIN detection and reporting increases through the use of standardized neuropathy assessment tools and grading scales.

Acknowledgements The authors would like to extend their gratitude to Conni Skrubbeltrang, Medical Library, Aalborg University Hospital, Denmark for assistance in the systematic literature search process.
Authors' contribution MLM and HD contributed equally to this paper. MLM and HD performed the literature search, screened the articles, and wrote the paper. All authors designed the study and critically revised and approved the final manuscript.

\section{Compliance with ethical standards}

Conflict of interest Author M.L.M declares that she has no conflict of interest. Author H.D declares that she has no conflict of interest. Author N.E declares that he has no conflict of interest. Author P.J declares that he has no conflict of interest. Author J.M declares that he has no conflict of interest. Author K.D declares that she has no conflict of interest.

Open Access This article is distributed under the terms of the Creative Commons Attribution 4.0 International License (http://creativeco mmons.org/licenses/by/4.0/), which permits unrestricted use, distribution, and reproduction in any medium, provided you give appropriate credit to the original author(s) and the source, provide a link to the Creative Commons license, and indicate if changes were made.

\section{References}

1. Yang L, Yu L, Chen X, Hu Y, Wang B (2015) Clinical analysis of adverse drug reactions between vincristine and triazoles in children with acute lymphoblastic leukemia. Med Sci Monit 21:1656-1661. https://doi.org/10.12659/MSM.893142

2. Gidding CE, Kellie SJ, Kamps WA, de Graaf SS (1999) Vincristine revisited. Crit Rev Oncol Hematol 29(3):267-287

3. Correia JJ (1991) Effects of antimitotic agents on tubulin-nucleotide interactions. Pharmacol Ther 52(2):127-147

4. Gascoigne KE, Taylor SS (2008) Cancer cells display profound intra- and interline variation following prolonged exposure to antimitotic drugs. Cancer Cell 14(2):111-122. https://doi. org/10.1016/j.ccr.2008.07.002

5. Gutierrez-Camino A, Umerez M, Martin-Guerrero I, Garcia de Andoin N, Santos B, Sastre A, Echebarria-Barona A, Astigarraga I, Navajas A, Garcia-Orad A (2017) Mir-pharmacogenetics of vincristine and peripheral neurotoxicity in childhood B-cell acute lymphoblastic leukemia. Pharmacogenom J. https://doi. org/10.1038/s41397-017-0003-3

6. Utsu Y, Takaishi K, Inagaki S, Arai H, Yuasa H, Masuda S, Matsuura Y, Aotsuka N, Wakita H (2016) Influence of dose reduction of vincristine in R-CHOP on outcomes of diffuse large B cell lymphoma. Ann Hematol 95(1):41-47. https://doi.org/10.1007/ s00277-015-2514-9

7. Morth C, Valachis A, Sabaa AA, Molin D, Flogegard M, Enblad $G$ (2018) Does the omission of vincristine in patients with diffuse large B cell lymphoma affect treatment outcome? Ann Hematol 97(11):2129-2135. https://doi.org/10.1007/s00277-018-3437-z

8. Chan SY, Worth R, Ochs S (1980) Block of axoplasmic transport in vitro by vinca alkaloids. J Neurobiol 11(3):251-264. https:// doi.org/10.1002/neu.480110304

9. Kavcic M, Koritnik B, Krzan M, Velikonja O, Prelog T, Stefanovic M, Debeljak M, Jazbec J (2017) Electrophysiological studies to detect peripheral neuropathy in children treated with vincristine. J Pediatr Hematol Oncol 39(4):266-271. https://doi. org/10.1097/MPH.0000000000000825

10. Mokhtar GM, Shaaban SY, Elbarbary NS, Fayed WA (2010) A trial to assess the efficacy of glutamic acid in prevention of vincristine-induced neurotoxicity in pediatric malignancies: a 
pilot study. J Pediatr Hematol Oncol 32(8):594-600. https://doi. org/10.1097/MPH.0b013e3181e9038d

11. El Hayek M, Trad O, Jamil A (2005) Vincristine-induced urinary bladder paralysis. J Pediatr Hematol Oncol 27(5):286-287. https ://doi.org/10.1097/01.mph.0000165130.21539.a3

12. Adhikari S, Dongol RM, Hewett Y, Shah BK (2014) Vincristineinduced blindness: a case report and review of literature. Anticancer Res 34(11):6731-6733

13. Sanderson PA, Kuwabara T, Cogan DG (1976) Optic neuropathy presumably caused by vincristine therapy. Am J Ophthalmol 81(2):146-150

14. Palkar AH, Nair AG, Desai RJ, Potdar NA, Shinde CA (2015) Vincristine-induced neuropathy presenting as ptosis and ophthalmoplegia in a 2-year-old boy. J Pediatr Ophthalmol Strabismus 52:34-37. https://doi.org/10.3928/01913913-20150629-01

15. Bay A, Yilmaz C, Yilmaz N, Oner AF (2006) Vincristine induced cranial polyneuropathy. Indian J Pediatr 73(6):531533. https://doi.org/10.1007/bf02759902

16. Soysal T, Ferhanoglu B, Bilir M, Akman N (1993) Oculomotor nerve palsy associated with vincristine treatment. Acta Haematol 90(4):209-210

17. Lash SC, Williams CPR, Marsh CS, Crithchley C, Hodgkins PR, MacKie EJ (2004) Acute sixth-nerve palsy after vincristine therapy. J AAPOS 8(1):67-68. https://doi.org/10.1016/j.jaapo s.2003.07.010

18. Toker E, Yenice O, Ogut MS (2004) Isolated abducens nerve palsy induced by vincristine therapy. J AAPOS 8(1):69-71. https://doi.org/10.1016/s1091853103003239

19. Ngamphaiboon N, Sweeney R, Wetzler M, Wang ES (2010) Pyridoxine treatment of vincristine-induced cranial polyneuropathy in an adult patient with acute lymphocytic leukemia: case report and review of the literature. Leuk Res 34(8):e194e196. https://doi.org/10.1016/j.leukres.2010.01.026

20. Mahajan SL, Ikeda Y, Myers TJ, Baldini MG (1981) Acute acoustic nerve palsy associated with vincristine therapy. Cancer 47(10):2404-2406

21. Riga M, Psarommatis I, Korres S, Varvutsi M, Giotakis I, Apostolopoulos N, Ferekidis E (2007) Neurotoxicity of vincristine on the medial olivocochlear bundle. Int J Pediatr Otorhinolaryngol 71(1):63-69. https://doi.org/10.1016/j.ijpor 1.2006.09.001

22. Latiff ZA, Kamal NA, Jahendran J, Alias H, Goh BS, Syed Zakaria SZ, Jamal R (2010) Vincristine-induced vocal cord palsy: case report and review of the literature. J Pediatr Hematol Oncol 32(5):407-410. https://doi.org/10.1097/MPH.0b013e3181e0158 4

23. Whittaker JA, Griffith IP (1977) Recurrent laryngeal nerve paralysis in patients receiving vincristine and vinblastine. BMJ 1(6071):1251-1252

24. Scheithauer W, Ludwig H, Maida E (1985) Acute encephalopathy associated with continuous vincristine sulfate combination therapy: case report. Invest New Drugs 3(3):315-318

25. How J, Blattner M, Fowler S, Wang-Gillam A, Schindler SE (2016) Chemotherapy-associated posterior reversible encephalopathy syndrome: a case report and review of the literature. Neurologist 21(6):112-117. https://doi.org/10.1097/nrl.00000 00000000105

26. Tomiwa K, Mikawa H, Hazama F, Yazawa K, Hosoya R, Ohya T, Nishimura K (1983) Syndrome of inappropriate secretion of antidiuretic hormone caused by vincristine therapy: a case report of the neuropathology. J Neurol 229(4):267-272

27. Robertson GL, Bhoopalam N, Zelkowitz LJ (1973) Vincristine neurotoxicity and abnormal secretion of antidiuretic hormone. Arch Intern Med 132(5):717-720

28. Kellie SJ, Barbaric D, Koopmans P, Earl J, Carr DJ, de Graaf SS (2002) Cerebrospinal fluid concentrations of vincristine after bolus intravenous dosing: a surrogate marker of brain penetration. Cancer 94(6): 1815-1820

29. Moghrabi A, Levy DE, Asselin B, Barr R, Clavell L, Hurwitz C, Samson Y, Schorin M, Dalton VK, Lipshultz SE, Neuberg DS, Gelber RD, Cohen HJ, Sallan SE, Silverman LB (2007) Results of the Dana-Farber Cancer Institute ALL Consortium Protocol 95-01 for children with acute lymphoblastic leukemia. Blood 109(3):896-904. https://doi.org/10.1182/blood-2006-06-027714

30. Kautio AL, Haanpää M, Kautiainen H, Kalso E, Saarto T (2011) Burden of chemotherapy-induced neuropathy-a cross-sectional study. Support Care Cancer 19(12):1991-1996. https://doi. org/10.1007/s00520-010-1043-2

31. Moher D, Liberati A, Tetzlaff J, Altman DG (2009) Preferred reporting items for systematic reviews and meta-analyses: the prisma statement. Ann Intern Med 151(4):264-269. https://doi. org/10.7326/0003-4819-151-4-200908180-00135

32. Lieber S, Blankenburg M, Apel K, Hirschfeld G, Hernaiz Driever P, Reindl T (2018) Small-fiber neuropathy and pain sensitization in survivors of pediatric acute lymphoblastic leukemia. Eur J Paediatr Neurol EJPN 22(3):457-469. https://doi.org/10.1016/j. ejpn.2017.12.019

33. Gilchrist LS, Tanner L (2013) The pediatric-modified total neuropathy score: a reliable and valid measure of chemotherapy-induced peripheral neuropathy in children with non-CNS cancers. Support Care Cancer 21(3):847-856. https://doi. org/10.1007/s00520-012-1591-8

34. Gilchrist LS, Marais L, Tanner L (2014) Comparison of two chemotherapy-induced peripheral neuropathy measurement approaches in children. Support Care Cancer 22(2):359-366. https://doi.org/10.1007/s00520-013-1981-6

35. Lavoie Smith EM, Li L, Hutchinson RJ, Ho R, Burnette WB, Wells E, Bridges C, Renbarger J (2013) Measuring vincristineinduced peripheral neuropathy in children with acute lymphoblastic leukemia. Cancer Nurs 36(5):E49-E60. https://doi. org/10.1097/NCC.0b013e318299ad23

36. Hirvonen HE, Salmi TT, Heinonen E, Antila KJ, Valimaki IA (1989) Vincristine treatment of acute lymphoblastic leukemia induces transient autonomic cardioneuropathy. Cancer 64(4):801-805

37. Guiheneuc P, Ginet J, Groleau JY, Rojouan J (1980) Early phase of vincristine neuropathy in man. Electrophysiological evidence for a dying-back phenomenon, with transitory enhancement of spinal transmission of the monosynaptic reflex. J Neurol Sci 45(2-3):355-366

38. Toopchizadeh V, Barzegar M, Rezamand A, Feiz AH (2009) Electrophysiological consequences of vincristine contained chemotherapy in children: a cohort study. J Pediatr Neurol 7(4):351-356. https://doi.org/10.3233/JPN-2009-0333

39. Courtemanche H, Magot A, Ollivier Y, Rialland F, LeclairVisonneau L, Fayet G, Camdessanche JP, Pereon Y (2015) Vincristine-induced neuropathy: atypical electrophysiological patterns in children. Muscle Nerve 52(6):981-985. https://doi. org/10.1002/mus. 24647

40. Ramchandren S, Leonard M, Mody RJ, Donohue JE, Moyer J, Hutchinson R, Gurney JG (2009) Peripheral neuropathy in survivors of childhood acute lymphoblastic leukemia. J Periph Nerv Syst JPNS 14(3):184-189. https://doi.org/10.111 1/j.1529-8027.2009.00230.x

41. Kava M, Walsh P, SrinivasJois R, Cole C, Lewis B, Nagarajan L (2017) Clinical and electrophysiological characteristics of vincristine induced peripheral neuropathy in children during cancer chemotherapy: does vitamin E have a role. JICNA 17 (75)

42. Postma TJ, Aaronson NK, Heimans JJ, Muller MJ, Hildebrand JG, Delattre JY, Hoang-Xuan K, Lanteri-Minet M, Grant R, Huddart R, Moynihan C, Maher J, Lucey R (2005) The development of an EORTC quality of life questionnaire to assess 
chemotherapy-induced peripheral neuropathy: the QLQ-CIPN20. Eur J Cancer (Oxford, England: 1990) 41(8):1135-1139. https:// doi.org/10.1016/j.ejca.2005.02.012

43. Le-Rademacher J, Kanwar R, Seisler D, Pachman DR, Qin R, Abyzov A, Ruddy KJ, Banck MS, Lavoie Smith EM, Dorsey SG, Aaronson NK, Sloan J, Loprinzi CL, Beutler AS (2017) Patient-reported (EORTC QLQ-CIPN20) versus physicianreported (CTCAE) quantification of oxaliplatin- and paclitaxel/ carboplatin-induced peripheral neuropathy in NCCTG/Alliance clinical trials. Supportive Care Cancer 25(11):3537-3544. https ://doi.org/10.1007/s00520-017-3780-y

44. Anghelescu DL, Faughnan LG, Jeha S, Relling MV, Hinds PS, Sandlund JT, Cheng C, Pei D, Hankins G, Pauley JL, Pui CH (2011) Neuropathic pain during treatment for childhood acute lymphoblastic leukemia. Pediatr Blood Cancer 57(7):1147-1153. https://doi.org/10.1002/pbc.23039

45. Jain P, Gulati S, Toteja GS, Bakhshi S, Seth R, Pandey RM (2015) Serum alpha tocopherol, vitamin B12, and folate levels in childhood acute lymphoblastic leukemia survivors with and without neuropathy. J Child Neurol 30(6):786-788. https://doi. org/10.1177/0883073814535495

46. Desai ZR, Van den Berg HW, Bridges JM, Shanks RG (1982) Can severe vincristine neurotoxicity be prevented? Cancer Chemother Pharmacol 8(2):211-214

47. Brunello A, Kapoor R, Extermann M (2011) Hyperglycemia during chemotherapy for hematologic and solid tumors is correlated with increased toxicity. Am J Clin Oncol 34(3):292-296. https:// doi.org/10.1097/COC.0b013e3181e1d0c0

48. Weiser MA, Cabanillas ME, Konopleva M, Thomas DA, Pierce SA, Escalante CP, Kantarjian HM, O'Brien SM (2004) Relation between the duration of remission and hyperglycemia during induction chemotherapy for acute lymphocytic leukemia with a hyperfractionated cyclophosphamide, vincristine, doxorubicin, and dexamethasone/methotrexate-cytarabine regimen. Cancer 100(6):1179-1185. https://doi.org/10.1002/cncr.20071

49. Kanbayashi Y, Hosokawa T, Okamoto K, Konishi H, Otsuji E, Yoshikawa T, Takagi T, Taniwaki M (2010) Statistical identification of predictors for peripheral neuropathy associated with administration of bortezomib, taxanes, oxaliplatin or vincristine using ordered logistic regression analysis. Anticancer Drugs 21(9):877-881. https://doi.org/10.1097/CAD.0b013e32833db89 d

50. Ibañez-Juliá MJ, Berzero G, Reyes-Botero G, Maisonobe T, Lenglet T, Slim M, Louis S, Balaguer A, Sanson M, Le Guern E, Latour P, Ricard D, Stojkovic T, Psimaras D (2018) Antineoplastic agents exacerbating Charcot Marie Tooth disease: red flags to avoid permanent disability. Acta Oncol 57(3):403-411. https ://doi.org/10.1080/0284186X.2017.1415462

51. Chauvenet AR, Shashi V, Selsky C, Morgan E, Kurtzberg J, Bell B (2003) Vincristine-induced neuropathy as the initial presentation of Charcot-Marie-Tooth disease in acute lymphoblastic leukemia: a Pediatric Oncology Group study. J Pediatr Hematol Oncol 25(4):316-320. https://doi.org/10.1097/00043426-20030 4000-00010

52. Re D, Schwenk A, Hegener P, Bamborschke S, Diehl V, Tesch H (2000) Guillain-Barre syndrome in a patient with non-Hodgkin's lymphoma. Ann Oncol 11(2):217-220

53. Bhushan B, Bhargava A, Kasundra GM, Shubhakaran K, Sood I (2015) Guillain-Barre syndrome in acute lymphoblastic leukemia: causal or coincidental. J Pediatr Neurosci 10(1):64-66. https ://doi.org/10.4103/1817-1745.154358

54. Okada N, Hanafusa T, Sakurada T, Teraoka K, Kujime T, Abe M, Shinohara Y, Kawazoe K, Minakuchi K (2014) Risk factors for early-onset peripheral neuropathy caused by vincristine in patients with a first administration of R-CHOP or R-CHOP-like chemotherapy. J Clin Med Res 6(4):252-260. https://doi. org/10.14740/jocmr1856w

55. Aplenc R, Glatfelter W, Han P, Rappaport E, La M, Cnaan A, Blackwood MA, Lange B, Rebbeck T (2003) CYP3A genotypes and treatment response in paediatric acute lymphoblastic leukaemia. Br J Haematol 122(2):240-244. https://doi.org/10.104 6/j.1365-2141.2003.04430.x

56. Kishi S, Cheng C, French D, Pei D, Das S, Cook EH, Hijiya N, Rizzari C, Rosner GL, Frudakis T, Pui CH, Evans WE, Relling MV (2007) Ancestry and pharmacogenetics of antileukemic drug toxicity. Blood 109(10):4151-4157. https://doi. org/10.1182/blood-2006-10-054528

57. Renbarger JL, McCammack KC, Rouse CE, Hall SD (2008) Effect of race on vincristine-associated neurotoxicity in pediatric acute lymphoblastic leukemia patients. Pediatr Blood Cancer 50(4):769-771. https://doi.org/10.1002/pbc.21435

58. Broyl A, Corthals SL, Jongen JL, van der Holt B, Kuiper R, de Knegt Y, van Duin M, el Jarari L, Bertsch U, Lokhorst HM, Durie BG, Goldschmidt H, Sonneveld P (2010) Mechanisms of peripheral neuropathy associated with bortezomib and vincristine in patients with newly diagnosed multiple myeloma: a prospective analysis of data from the HOVON-65/GMMG-HD4 trial. Lancet Oncol 11(11):1057-1065. https://doi.org/10.1016/ s1470-2045(10)70206-0

59. Egbelakin A, Ferguson MJ, MacGill EA, Lehmann AS, Topletz AR, Quinney SK, Li L, McCammack KC, Hall SD, Renbarger JL (2011) Increased risk of vincristine neurotoxicity associated with low CYP3A5 expression genotype in children with acute lymphoblastic leukemia. Pediatr Blood Cancer 56(3):361-367. https://doi.org/10.1002/pbc.22845

60. Ceppi F, Langlois-Pelletier C, Gagne V, Rousseau J, Ciolino C, De Lorenzo S, Kevin KM, Cijov D, Sallan SE, Silverman LB, Neuberg D, Kutok JL, Sinnett D, Laverdiere C, Krajinovic M (2014) Polymorphisms of the vincristine pathway and response to treatment in children with childhood acute lymphoblastic leukemia. Pharmacogenomics 15(8):1105-1116. https://doi. org/10.2217/pgs.14.68

61. Diouf B, Crews KR, Lew G, Pei D, Cheng C, Bao J, Zheng JJ, Yang W, Fan Y, Wheeler HE, Wing C, Delaney SM, Komatsu M, Paugh SW, McCorkle JR, Lu X, Winick NJ, Carroll WL, Loh ML, Hunger SP, Devidas M, Pui CH, Dolan ME, Relling MV, Evans WE (2015) Association of an inherited genetic variant with vincristine-related peripheral neuropathy in children with acute lymphoblastic leukemia. JAMA 313(8):815-823. https://doi.org/10.1001/jama.2015.0894

62. Stock W, Diouf B, Crews KR, Pei D, Cheng C, Laumann K, Mandrekar SJ, Luger S, Advani A, Stone RM, Larson RA, Evans WE (2017) An inherited genetic variant in CEP72 promoter predisposes to vincristine-induced peripheral neuropathy in adults with acute lymphoblastic leukemia. Clin Pharmacol Ther 101(3):391-395. https://doi.org/10.1002/cpt.506

63. Gutierrez-Camino A, Martin-Guerrero I, Lopez-Lopez E, Echebarria-Barona A, Zabalza I, Ruiz I, Guerra-Merino I, Garcia-Orad A (2016) Lack of association of the CEP72 RS924607 TT genotype with vincristine-related peripheral neuropathy during the early phase of pediatric acute lymphoblastic leukemia treatment in a Spanish population. Pharmacogenet Genom 26(2):100-102. https://doi.org/10.1097/FPC.0000000000 000191

64. Sims RP (2016) The effect of race on the CYP3A-mediated metabolism of vincristine in pediatric patients with acute lymphoblastic leukemia. J Oncol Pharm Pract 22(1):76-81. https://doi. org/10.1177/1078155214553143

65. Lopez-Lopez E, Gutierrez-Camino A, Astigarraga I, Navajas A, Echebarria-Barona A, Garcia-Miguel P, Garcia de Andoin N, Lobo C, Guerra-Merino I, Martin-Guerrero I, Garcia-Orad A 
(2016) Vincristine pharmacokinetics pathway and neurotoxicity during early phases of treatment in pediatric acute lymphoblastic leukemia. Pharmacogenomics 17(7):731-741. https://doi. org/10.2217/pgs-2016-0001

66. Kayilioglu H, Kocak U, Kan Karaer D, Percin EF, Sal E, Tekkesin F, Isik M, Oner N, Belen FB, Yilmaz Keskin E, Okur A, Albayrak M, Kaya Z, Pinarli FG, Yenicesu I, Karadeniz C, Oguz A, Gursel T (2017) Association of CYP3A5 expression and vincristine neurotoxicity in pediatric malignancies in Turkish population. J Pediatr Hematol Oncol 39(6):458-462. https://doi. org/10.1097/mph.0000000000000910

67. Skiles JL, Chiang C, Li CH, Martin S, Smith EL, Olbara G, Jones DR, Vik TA, Mostert S, Abbink F, Kaspers GJ, Li L, Njuguna F, Sajdyk TJ, Renbarger JL (2018) CYP3A5 genotype and its impact on vincristine pharmacokinetics and development of neuropathy in Kenyan children with cancer. Pediatr Blood Cancer. https://doi.org/10.1002/pbc.26854

68. Wright GEB, Amstutz U, Drogemoller BI, Shih J, Rassekh SR, Hayden MR, Carleton BC, Ross CJD (2018) Pharmacogenomics of vincristine-induced peripheral neuropathy implicates pharmacokinetic and inherited neuropathy genes. Clin Pharmacol Ther. https://doi.org/10.1002/cpt.1179

69. Smitherman AB, Faircloth CB, Deal A, Troy M, Gold SH (2017) Vincristine toxicity with co-administration of fluconazole during induction therapy for pediatric acute lymphoblastic leukemia. Pediatr Blood Cancer. https://doi.org/10.1002/pbc.26525

70. Takahashi N, Kameoka Y, Yamanaka Y, Ubukawa K, Saito K, Fujishima M, Fujishima N, Saito H, Hirokawa M, Scott SA, Sawada K (2008) Itraconazole oral solution enhanced vincristine neurotoxicity in five patients with malignant lymphoma. Intern Med (Tokyo, Japan) 47(7):651-653

71. Nikanjam M, Sun A, Albers M, Mangalindin K, Song E, Vempaty H, Sam D, Capparelli EV (2018) Vincristine-associated neuropathy with antifungal usage: a kaiser northern California experience. J Pediatr Hematol Oncol 40(5):e273-e277. https:// doi.org/10.1097/MPH.0000000000001220

72. Bohme A, Ganser A, Hoelzer D (1995) Aggravation of vincristine-induced neurotoxicity by itraconazole in the treatment of adult ALL. Ann Hematol 71(6):311-312

73. Teusink AC, Ragucci D, Shatat IF, Kalpatthi R (2012) Potentiation of vincristine toxicity with concomitant fluconazole prophylaxis in children with acute lymphoblastic leukemia. Pediatr Hematol Oncol 29(1):62-67. https://doi.org/10.3109/08880 018.2011 .624163

74. Gillies J, Hung KA, Fitzsimons E, Soutar R (1998) Severe vincristine toxicity in combination with itraconazole. Clin Lab Haematol 20(2):123-124

75. Kamaluddin M, McNally P, Breatnach F, O'Marcaigh A, Webb D, O’Dell E, Scanlon P, Butler K, O’Meara A (2001) Potentiation of vincristine toxicity by itraconazole in children with lymphoid malignancies. Acta Paediatr 90(10):1204-1207

76. van Schie RM, Bruggemann RJ, Hoogerbrugge PM, te Loo DM (2011) Effect of azole antifungal therapy on vincristine toxicity in childhood acute lymphoblastic leukaemia. J Antimicrob Chemother 66(8):1853-1856. https://doi.org/10.1093/jac/dkr223

77. Cheung MC, Hicks LK, Leitch HA (2010) Excessive neurotoxicity with ABVD when combined with protease inhibitor-based antiretroviral therapy in the treatment of AIDS-related Hodgkin lymphoma. Clin Lymphoma Myeloma Leukemia 10(2):E22E25. https://doi.org/10.3816/CLML.2010.n.025

78. Ezzat HM, Cheung MC, Hicks LK, Boro J, Montaner JS, Lima VD, Harris M, Leitch HA (2012) Incidence, predictors and significance of severe toxicity in patients with human immunodeficiency virus-associated Hodgkin lymphoma. Leukemia Lymphoma 53(12):2390-2396. https://doi.org/10.3109/10428 194.2012.697560
79. Weintraub M, Adde MA, Venzon DJ, Shad AT, Horak ID, Neely JE, Seibel NL, Gootenberg J, Arndt C, Nieder ML, Magrath IT (1996) Severe atypical neuropathy associated with administration of hematopoietic colony-stimulating factors and vincristine. J Clin Oncol 14(3):935-940. https://doi.org/10.1200/ jco.1996.14.3.935

80. Ryan JR, Emami A (1983) Vincristine neurotoxicity with residual equinocavus deformity in children with acute leukemia. Cancer 51(3):423-425

81. van Kooten B, van Diemen HA, Groenhout KM, Huijgens PC, Ossenkoppele GJ, Nauta JJ, Heimans JJ (1992) A pilot study on the influence of a corticotropin (4-9) analogue on Vinca alkaloid-induced neuropathy. Arch Neurol 49(10):1027-1031

82. Akbayram S, Akgun C, Dogan M, Sayin R, Caksen H, Oner AF (2010) Use of pyridoxine and pyridostigmine in children with vincristine-induced neuropathy. Indian J Pediatr 77(6):681-683. https://doi.org/10.1007/s12098-010-0096-Z

83. Bradfield SM, Sandler E, Geller T, Tamura RN, Krischer JP (2015) Glutamic acid not beneficial for the prevention of vincristine neurotoxicity in children with cancer. Pediatr Blood Cancer 62(6):1004-1010. https://doi.org/10.1002/pbc.25384

84. Sands S, Ladas EJ, Kelly KM, Weiner M, Lin M, Ndao DH, Dave A, Vahdat LT, Bender JG (2017) Glutamine for the treatment of vincristine-induced neuropathy in children and adolescents with cancer. Support Care Cancer 25(3):701-708. https://doi. org/10.1007/s00520-016-3441-6

85. Koeppen S, Verstappen CC, Korte R, Scheulen ME, Strumberg D, Postma TJ, Heimans JJ, Huijgens PC, Kiburg B, RenzingKohler K, Diener HC (2004) Lack of neuroprotection by an ACTH (4-9) analogue. A randomized trial in patients treated with vincristine for Hodgkin's or non-Hodgkin's lymphoma. J Cancer Res Clin Oncol 130(3):153-160. https://doi.org/10.1007/ s00432-003-0524-9

86. Jain P, Gulati S, Seth R, Bakhshi S, Toteja GS, Pandey RM (2014) Vincristine-induced neuropathy in childhood all (acute lymphoblastic leukemia) survivors: prevalence and electrophysiological characteristics. J Child Neurol 29(7):932-937. https:// doi.org/10.1177/0883073813491829

87. Harila-Saari AH, Vainionpää LK, Kovala TT, Tolonen EU, Lanning BM (1998) Nerve lesions after therapy for childhood acute lymphoblastic leukemia. Cancer 82(1):200-207. https:// doi.org/10.1002/(SICI)1097-0142(19980101)82:1\%3c200:AIDCNCR87\%3e3.0.CO;2-5

88. Watkins SM, Griffin JP (1978) High incidence of vincristineinduced neuropathy in lymphomas. BMJ 1(6113):610-612

89. Tay CG, Lee VWM, Ong LC, Goh KJ, Ariffin H, Fong CY (2017) Vincristine-induced peripheral neuropathy in survivors of childhood acute lymphoblastic leukaemia. Pediatric Blood Cancer. https://doi.org/10.1002/pbc.26471

90. Postma TJ, Benard BA, Huijgens PC, Ossenkoppele GJ, Heimans JJ (1993) Long-term effects of vincristine on the peripheral nervous system. J Neurooncol 15(1):23-27

91. Verstappen CC, Koeppen S, Heimans JJ, Huijgens PC, Scheulen ME, Strumberg D, Kiburg B, Postma TJ (2005) Dose-related vincristine-induced peripheral neuropathy with unexpected offtherapy worsening. Neurology 64(6):1076-1077. https://doi. org/10.1212/01.wnl.0000154642.45474.28

92. Haim N, Epelbaum R, Ben-Shahar M, Yarnitsky D, Simri W, Robinson E (1994) Full dose vincristine (without 2-mg dose limit) in the treatment of lymphomas. Cancer 73(10):2515-2519

93. Lavoie Smith EM, Li L, Chiang C, Thomas K, Hutchinson RJ, Wells EM, Ho RH, Skiles J, Chakraborty A, Bridges CM, Renbarger J (2015) Patterns and severity of vincristine-induced peripheral neuropathy in children with acute lymphoblastic leukemia. J Periph Nerv Syst 20(1):37-46. https://doi.org/10.1111/ jns.12114 
94. Kim BJ, Park HR, Roh HJ, Jeong DS, Kim BS, Park KW, Cho SC, So YT, Oh SY, Kim SJ (2010) Chemotherapy-related polyneuropathy may deteriorate quality of life in patients with B-cell lymphoma. Q Life Res 19(8):1097-1103. https://doi.org/10.1007/ s11136-010-9670-0

95. Vainionpaa L (1993) Clinical neurological findings of children with acute lymphoblastic leukaemia at diagnosis and during treatment. Eur J Pediatr 152(2):115-119. https://doi.org/10.1007/ BF02072486

96. Gilchrist LS, Tanner LR, Ness KK (2017) Short-term recovery of chemotherapy-induced peripheral neuropathy after treatment for pediatric non-CNS cancer. Pediatr Blood Cancer 64(1):180-187. https://doi.org/10.1002/pbc.26204

97. Miller AB, Hoogstraten B, Staquet M, Winkler A (1981) Reporting results of cancer treatment. Cancer 47(1):207-214

98. Trotti A, Colevas AD, Setser A, Basch E (2007) Patient-reported outcomes and the evolution of adverse event reporting in oncology. J Clin Oncol 25(32):5121-5127. https://doi.org/10.1200/ jco.2007.12.4784

99. Cavaletti G, Frigeni B, Lanzani F, Piatti M, Rota S, Briani C, Zara G, Plasmati R, Pastorelli F, Caraceni A, Pace A, Manicone M, Lissoni A, Colombo N, Bianchi G, Zanna C (2007) The Total Neuropathy Score as an assessment tool for grading the course of chemotherapy-induced peripheral neurotoxicity: comparison with the National Cancer Institute-Common Toxicity Scale. J Periph Nerv Syst JPNS 12(3):210-215. https://doi.org/10.111 1/j.1529-8027.2007.00141.x

100. Gilchrist L (2012) Chemotherapy-induced peripheral neuropathy in pediatric cancer patients. Semin Pediatr Neurol 19(1):9-17. https://doi.org/10.1016/j.spen.2012.02.011

101. Bakogeorgos M, Georgoulias V (2017) Risk-reduction and treatment of chemotherapy-induced peripheral neuropathy. Expert Rev Anticancer Ther 17(11):1045-1060. https://doi. org/10.1080/14737140.2017.1374856

102. Hussain M, Wozniak AJ, Edelstein MB (1993) Neurotoxicity of antineoplastic agents. Crit Rev Oncol Hematol 14(1):61-75

103. Wolf S, Barton D, Kottschade L, Grothey A, Loprinzi C (2008) Chemotherapy-induced peripheral neuropathy: prevention and treatment strategies. Eur J Cancer 44(11):1507-1515. https://doi. org/10.1016/j.ejca.2008.04.018

104. Quasthoff S, Hartung HP (2002) Chemotherapy-induced peripheral neuropathy. J Neurol 249(1):9-17

105. Grisold W, Cavaletti G, Windebank AJ (2012) Peripheral neuropathies from chemotherapeutics and targeted agents: diagnosis, treatment, and prevention. Neuro-oncology 14(Suppl. 4):45-54. https://doi.org/10.1093/neuonc/nos203

106. Gulliford MC, Charlton J, Latinovic R (2006) Risk of diabetes associated with prescribed glucocorticoids in a large population. Diabetes Care 29(12):2728-2729. https://doi.org/10.2337/ dc06-1499

107. Dennison JB, Kulanthaivel P, Barbuch RJ, Renbarger JL, Ehlhardt WJ, Hall SD (2006) Selective metabolism of vincristine in vitro by CYP3A5. Drug Metab Dispos 34(8):1317-1327. https ://doi.org/10.1124/dmd.106.009902

108. Kuehl P, Zhang J, Lin Y, Lamba J, Assem M, Schuetz J, Watkins PB, Daly A, Wrighton SA, Hall SD, Maurel P, Relling M, Brimer C, Yasuda K, Venkataramanan R, Strom S, Thummel K, Boguski MS, Schuetz E (2001) Sequence diversity in CYP3A promoters and characterization of the genetic basis of polymorphic CYP3A5 expression. Nat Genet 27(4):383-391. https://doi. org/10.1038/86882

109. Venkatakrishnan K, von Moltke LL, Greenblatt DJ (2000) Effects of the antifungal agents on oxidative drug metabolism: clinical relevance. Clin Pharmacokinet 38(2):111-180. https://doi. org/10.2165/00003088-200038020-00002

110. Wang E-j, Lew K, Casciano CN, Clement RP, Johnson WW (2002) Interaction of common azole antifungals with P glycoprotein. Antimicrob Agents Chemother 46(1):160-165. https:// doi.org/10.1128/AAC.46.1.160-165.2002

Publisher's Note Springer Nature remains neutral with regard to jurisdictional claims in published maps and institutional affiliations. 